\title{
Uma genealogia das teses de John Dewey acerca da arte na educação ${ }^{1}$
}

\section{A genealogy of John Dewey's theses on art in education}

\author{
Aline Hernandes de Carvalho* \\ Marcus Vinicius da Cunha*
}

\begin{abstract}
RESUMO
Este trabalho considera que a elaboração da teoria estética de John Dewey, apresentada no livro "Arte como experiência", publicado em 1934, decorre de uma série de ensaios da década de 1920 - "Experience, nature and art" [Experiência, natureza e arte], "Individuality and experience" [Individualida e experiência], "Affective thought" [Pensamento afetivo] e "Art in educationeducation in art" [Arte em educação - educação em arte]. O trabalho analisa cada um desses ensaios individualmente e relaciona os seus conteúdos com os temas centrais do livro, com o propósito de oferecer novas diretrizes para o trabalho docente na atualidade.
\end{abstract}

Palavras-chaves: John Dewey. Ensino de arte. Estética. Trabalho docente

\begin{abstract}
This work considers that the elaboration of John Dewey's aesthetic theory, presented in the book "Art as experience", published in 1934, derives from a series of essays from the 1920s - "Experience, nature and art", "Individuality and experience", "Affective thought," and "Art in education-education in art". The work analyzes each one of these essays individually and relates its contents to the central themes of the book to offer new guidelines for the teaching work today.
\end{abstract}

Keywords: John Dewey. Art Education. Aesthetics. Teaching Work.

1 As pesquisas que resultaram neste trabalho foram subsidiadas pelo Conselho Nacional de Desenvolvimento Científico e Tecnológico (CNPq).

* Universidade de São Paulo. Programa de Pós-Graduação em Educação. Ribeirão Preto, São Paulo, Brasil. E-mail: aline.hernandes.carvalho@usp.br - https://orcid.org/0000-0002-1069-8129 E-mail: mvcunha2@hotmail.com - https://orcid.org/0000-0001-8414-7306 


\section{Introdução}

Ana Mae Barbosa figura entre os expoentes do movimento de retomada das ideias de John Dewey (1859-1952) na educação brasileira, especialmente quanto à presença das artes nas práticas pedagógicas. Seu livro "Recorte e colagem" (BARBOSA, 1982), publicado no início da década de 1980 e editado mais tarde com o título "John Dewey e o ensino da arte no Brasil" (BARBOSA, 2002), é um marco desse movimento e referência indispensável a todos os interessados na busca por novos fundamentos para a renovação educacional.

As análises da autora sobre educação e as suas propostas para a arteeducação foram ampliadas nos anos seguintes - ver, por exemplo, Barbosa (1998, 2010, 2012) -, sempre em consonância com os princípios filosóficos deweyanos, com especial destaque para as teses contidas em "Arte como experiência" (DEWEY, 2010), de 1934. Situado no campo da estética, esse livro é visto por Barbosa como repleto de sugestões para os educadores. Sua publicação ocorreu quase vinte anos depois de "Democracia e educação" (DEWEY, 1959), de 1916, no qual se encontram as formulações definitivas do filósofo acerca de temáticas educacionais em conexão íntima com proposições de natureza política.

A cronologia das publicações educacionais de Dewey revela uma característica de seu método de produção intelectual. Durante aproximadamente dez anos a partir de 1894, Dewey dirigiu na Universidade de Chicago uma experiência inovadora, a Escola Laboratório, fundamentada no Pragmatismo. Valdemarin (2010) explica que, naquele período e imediatamente após, o filósofo elaborou vários textos motivado pela necessidade de refletir sobre as práticas desenvolvidas naquela escola, consolidando assim as suas teses educacionais ${ }^{2}$. Aqueles trabalhos serviram de base para obras mais elaboradas, a exemplo de "Como pensamos" (DEWEY, 1953), de 1910, do próprio "Democracia e educação" e, mesmo do tardio, "Experiência e educação" (DEWEY, 1971), de 1938.

Para obtermos um entendimento amplo das proposições de Dewey formuladas nessas e em outras produções de temática educacional, faz-se necessário recorrer à suas ideias filosóficas, uma vez que as teses deweyanas não consistem em simples pedagogia, tratando-se de um empenho reflexivo pedagógico e político dedicado a promover mudanças na teoria e na prática da

2 São dessa época, entre outros, "My pedagogic creed" (DEWEY, 2003e), "The school and Society" (DEWEY, 2003f) e "A criança e o programa escolar" (DEWEY, 1978), publicados respectivamente em 1897, 1899 e 1902. 
educação. Para esse mesmo fim, é aconselhável conhecer os textos decorrentes das experiências da Escola Laboratório, nos quais se pode identificar a gênese de suas ideias educacionais.

As considerações de Barbosa acerca das ideias deweyanas sugerem que, em temas concernentes a arte e arte-educação, Dewey pode ter seguido método semelhante ao que utilizou em sua produção educacional, evoluindo de trabalhos curtos a textos mais volumosos e mesclando reflexões concernentes à prática com análises de maior complexidade conceitual. Segundo a autora, "Experience, nature and art" (DEWEY, 1974), de 1925, e principalmente "Arte como experiência" representam a terceira fase de um desenvolvimento teórico iniciado com "The school and Society" (DEWEY, 2003f) e "Individuality and experience" (DEWEY, 2003c), publicados respectivamente em 1899 e 1926. Esse desenvolvimento avança em "Democracia e educação" e "Affective thought in logic and painting" (DEWEY, 2003a), de 1926 (BARBOSA, 1982, p. 45)3.

Excetuando-se "The school and society" e "Democracia e educação", os demais títulos acima mencionados são pouco conhecidos no Brasil por não abordarem, direta ou prioritariamente, temáticas relativas à educação - área que primeiramente absorveu Dewey neste país. Isto se aplica a "Arte como experiência", cujas contribuições vêm sendo retomadas no campo das artes, e em maior grau a "Experience, nature and art", "Individuality and experience" e "Affective thought", escassamente discutidos em nosso meio.

O presente artigo visa investigar em que medida se pode identificar nesses ensaios curtos a gênese de ideias aperfeiçoadas mais tarde por Dewey, compondo, assim, uma genealogia da teoria estética deweyana, tal como ocorreu com os textos educacionais precedentes a "Como pensamos" e "Democracia e educação". Para cumprir essa meta, faremos inicialmente uma breve apresentação de "Arte como experiência", para em seguida abordar individualmente cada um dos três ensaios acima citados, buscando relacionar as suas temáticas centrais com as do referido livro. Acrescentaremos a esse rol "Art in education - education in art" (DEWEY, 2003), publicado em 1926, na mesma época dos demais e com temática aproximada. Finalizaremos este trabalho discutindo as contribuições educacionais derivadas deste exame.

3 Esse último texto foi publicado no mesmo ano como "Affective thought", título que se firmou como definitivo. 


\section{Arte, experiência e educação}

Logo após deixar Chicago, Dewey ingressou em 1905 na Universidade de Colúmbia, Nova York, onde permaneceu como professor emérito depois de se aposentar, em 1930. Sua produção posterior inclui obras dedicadas a "consolidar e ampliar os parâmetros básicos de sua filosofia, tendo em vista as aceleradas mudanças havidas nas escolas e nos campos da ciência, da política e da cultura, de modo geral" (CUNHA, 2010, p. 16). Seus escritos mais importantes dessa época podem ser agrupados em três categorias - estudos educacionais, discussões filosóficas e análises de cunho político, social e cultural, sendo a maior parte de sua produção composta por trabalhos não diretamente ligados a educação.

O livro "Arte como experiência" foi publicado logo no início desse período, em 1934, como já foi dito. Na mesma década, Dewey escreveu outras obras igualmente relevantes, como "Logic: the theory of inquiry" (DEWEY, 2003d) e "Experiência e educação", ambas de 1938, e "Teoria da valoração" (DEWEY, 2009), de 1939. "Arte como experiência" não é um texto sobre educação, mas uma obra de filosofia, mais precisamente filosofia da arte, ou estética, sendo resultante de uma série de conferências proferidas pelo autor em 1931 na Universidade de Harvard (DEWEY, 2010).

O objetivo central desse livro é destacar o valor da experiência estética na criação e na fruição da arte e, de modo geral, na compreensão do mundo. Dewey "defende o vínculo indissolúvel entre o produtor, o produto e aqueles a quem o produto se destina", conexão que se estabelece pelo conceito de experiência, termo que, no interior de sua concepção filosófica, "não se reduz a vivências do indivíduo isolado" (CUNHA, 2015, p. 75-76). Para Dewey, "a compreensão da experiência estética verdadeira passa pela consideração de seu 'estado bruto' quanto às formas de ver e ouvir como geradoras de atenção e interesse", o que pode ocorrer "tanto a uma dona de casa regando as plantas do jardim quanto a alguém que observa as chamas crepitantes em uma lareira" (REIS; BAGOLIN, 2011, p. 315).

A arte, portanto, advém da experiência estética própria do ser humano, não se restringindo ao que usualmente se considera artístico, nem ao que se encontra exposto em museus para consumo das massas: "a arte que interessa realmente surge a partir do poder de realização de novas adaptações, perfazendo-se como experiência estética - portanto, significativa - em um tempo que é tão somente o de seu presente"; o que interessa nessa definição diz respeito ao "desfrute ou ao gozo" proporcionado pela experiência (REIS; BAGOLIN, 2011, p. 317). 
Em "Arte como experiência", Dewey discute a atividade artística no âmbito da vida sujeitada à produção industrial, tecendo uma crítica ao sistema produtivo massificado que reduz os produtos da arte a artigos de luxo para deleite das classes abastadas. A produção artística transforma-se cada vez mais em algo meramente mecânico:

O mecânico situa-se no polo oposto ao estético, e hoje a produção de bens é mecanizada. A liberdade de escolha permitida ao artesão que trabalhava com as mãos quase desapareceu, com a utilização geral das máquinas. A produção de objetos desfrutada na experiência direta pelos que, em alguma medida, possuem a capacidade de produzir artigos úteis, que expressam valores individuais, tornou-se um assunto especializado, distinto do funcionamento geral da produção. Provavelmente, esse é o fator mais importante na situação da arte na civilização atual (DEWEY, 2010, p. 573).

Embora "Arte como experiência" não mencione a educação com marcada ênfase, sua leitura pode ser útil para discutir as práticas formativas no contexto educacional mais amplo e, em específico, no espaço escolar. A obra traz "princípios baseados na definição de arte como experiência e forma de linguagem, oferecendo alicerces teóricos para que o educador construa, por si mesmo e com seus alunos, o edifício da educação" (ANDRADE; CUNHA, 2016, p. 311). Inspirado nas concepções estéticas deweyanas, o educador poderá refletir sobre as situações que o confrontam diariamente; se não possui as condições ideais para promover a experiência como gostaria, poderá se sentir desafiado a elaborar inovações capazes de superar o estado atual de seu ofício.

\section{O estético e o artístico}

O ensaio "Experience, nature and art", publicado em 1925, questiona a dualidade entre as chamadas artes úteis, exclusivamente voltadas à produção, e as belas artes, mostrando que ambas pertencem ao domínio da prática, e analisa a diferença entre o estético e o artístico, no intuito de identificar o que permite qualificar uma obra como arte genuína. Dewey (1974, p. 157) considera que as teorias contemporâneas da arte são baseadas nos ideais da Grécia Antiga, onde a arte era vista como ação própria de um "mundo meramente 
subjetivo, mutável e imperfeito". Em contrapartida, a ciência era entendida como "revelação da realidade", meio de acesso ao mundo como ele realmente é, livre das distorções causadas pelos desejos e preferências humanas. A arte era produção; a ciência, "contemplação".

Entre os gregos, a arte foi secundarizada em detrimento da ciência por ser concebida como atividade inerente a escravos, classe que realizava todo o trabalho necessário para que homens livres e cidadãos dele usufruíssem em posição de superioridade material e moral. $\mathrm{O}$ artista, aquele que produz com as próprias mãos, era visto como pertencente ao reino inferior da natureza e da experiência, ao passo que o conhecimento verdadeiro era posto como derivado da contemplação que revela, por si só, a natureza tal qual ela é. Segundo Dewey (1974), essa é a distinção que ainda se apresenta como força teórica dominante.

Os gregos respeitavam as artes úteis, mas as mantinham afastadas das belas artes. Classificavam o artista como criador ativo, e o espectador, como passivo, situando o primeiro acima do segundo, bem como o produtor acima do consumidor. Embora concebessem o conhecimento como contemplação, reconheciam que a ciência, como busca sistemática do conhecimento, é ativa, pertencendo, portanto, ao domínio da prática. Dewey (1974) avalia que essas afirmações contraditórias explicitam o erro cometido pelos gregos ao promoverem o isolamento entre conhecimento e prática, e diz que a discussão atual acerca da estética e da arte é inconsistente por confundir arte como processo de execução e arte como apreciação de produtos criados.

Essa discussão produz um divórcio entre o que é artístico, termo que designa as ações que resultam em uma obra, e o que é estético, palavra usada para determinar o valor do objeto criado, revelando um modo de pensar que evidencia a separação entre processo e produto. Dewey (1974, p. 159) explica que a degradação da arte e a do trabalho são processos paralelos; o dualismo entre arte e trabalho decorre de "defeitos na atual ordem econômica e social", a qual retira do trabalho qualquer "satisfação de desejo inteligente", o transformando em mera "confusão e extravagância".

Não pode haver uma verdadeira compreensão da prática ou da apreciação estética, enquanto a prática for, em grande medida, escravidão, e enquanto a "apreciação estética" for apenas uma das formas de distração de que se extraem os intervalos de descanso da escravidão (DEWEY, 1974, p. 159).

Em "Arte como experiência", o tema relativo ao equívoco contido nessa dicotomia é retomado de modo muito semelhante ao que se encontra em "Experience, nature and art". Dewey (2010) explica que a língua inglesa não tem 
uma palavra que designe, ao mesmo tempo, o que é estético e o que é artístico; os significados são separados, sendo o primeiro vocábulo usado para nomear o ato de percepção e prazer, e o segundo, o ato de produção. Por isso, muitas vezes o processo de produção e o de apreciação da arte são apartados, como se não se relacionassem mutuamente, visão que produz um efeito de superposição da arte ao material estético. As artes úteis são diferenciadas das belas-artes por serem entendidas como puramente práticas.

Dewey (2010) defende que toda arte, seja clássica ou tecnológica, denota um processo de fazer e criar, o que define tanto uma quanto outra como artes práticas. A diferença entre o estético e o artístico é julgada exclusivamente pelo gosto do consumidor, em sua percepção apreciativa, conferindo ao produto o caráter de mercadoria. Um mestre de cozinha pode cozinhar um espaguete com admiração, com amor, colocando no ato de produção características estéticas genuínas que qualificam o ato de cozinhar como estético. No entanto, o consumidor, sentado na mesa no restaurante, pode consumir o alimento com rapidez, como mero fazer rotineiro, sem realizar uma experiência estética.

Nessa ilustração, as ações do cozinheiro são artísticas e também estéticas, pois ao produzir para criar algo a ser desfrutado na experiência imediata da percepção, o cozinheiro incorpora o desejo de compartilhar a experiência pessoal de quem degusta seu produto. Embora esse desejo seja inerente ao ato de cozinhar para outrem, tratando-se, portanto, de um ato genuinamente estético, o consumidor pode valorizar apenas o produto final, o reduzindo ao status de mercadoria.

Para Dewey (2010), uma experiência totalmente prática, que se concentre apenas no fazer, pode ser estética. Se chegar a determinado fim, sem se refletir na consciência como consumação, se for apenas mecânica e não contribuir para a experiência, é apenas prática. Mas se os cursos da ação se compuserem em atos sucessivos, permeados por uma percepção de significado que cresce e se acumula em direção a um objetivo, a experiência é estética.

Dewey conclui dizendo que o que torna uma obra arte genuína não é o seu valor de utilidade, assim como não é o seu caráter contemplativo, mas o seu significado como experiência estética. $\mathrm{O}$ fazer de um artista não é melhor do que o fazer de um artesão, assim como as belas artes não são artes mais genuínas do que as artes úteis porque "qualquer atividade prática, desde que seja integrada e se mova por seu próprio impulso para a consumação, tem uma qualidade estética" (DEWEY, 2010, p. 115).

Abordagem semelhante encontra-se em "Experience, nature and art", quando Dewey (1974, p. 163-164) defende que as qualidades que distinguem o objeto estético, chamadas "formas significativas" por darem significado consumatório à experiência cotidiana, não são propriedades ou criações 
peculiares da estética e do artístico, mas qualidades que podem se manifestar em objetos e situações que proporcionam percepções agradáveis. É o caso de um artista que, mesmo sem conhecer as tais formas, pode selecioná-las por afinidade, ou que as conheça e utilize para criar algo totalmente diferente do que nossos olhos estão acostumados a ver, inaugura novos modos de percepção capazes de ampliar e enriquecer uma visão humana do mundo.

Dewey (1974, p. 164-165) conclui o ensaio de 1925 afirmando que a arte é grande na mesma proporção em que é universal, "na medida em que as uniformidades da natureza que ela revela e utiliza são extensas e profundas" e podem ser aplicadas a objetos e situações concretas. "Os únicos objetos, ideias, percepções, que permanecem sem vontade e não confirmados são aqueles que aguçam a nossa visão para novas e imprevisíveis formas de realização da verdade que transmitem". O componente "mágico" da poesia nada mais é do que a revelação do significado do velho representado pelo novo.

\section{Arte, ciência e educação}

Em "Affective thought", publicado em 1926, Dewey mostra que os fatores fisiológicos e os processos emocionais e imaginativos do ser humano trabalham conjuntamente e de modo complementar, tese que vai de encontro às correntes teóricas que os veem como desvinculados e valorizam os primeiros em detrimento dos segundos. Dewey (2003a, p. 106) se dispõe a discutir o assunto analisando os resultados de análises fisiológicas que exercem influência direta sobre "a arte e sua conexão com os processos normais da vida".

O ensaio analisa que as teorias tradicionais da filosofia e da psicologia nos habituaram a distinguir entre os processos orgânicos e fisiológicos e as "manifestações mais elevadas da cultura na ciência e na arte", o que traduz o tradicional dualismo entre corpo e mente. Fomos acostumados a separar as operações lógicas, de um lado, e os processos emocionais e os assuntos cotidianos, como a política e a religião, de outro. A dicotomia entre pensamento e afetividade, segundo Dewey (2003a, p. 105), é um dos fatores responsáveis pela "departamentalização da vida", mecanismo que segrega e secundariza as atividades que exercemos rotineiramente. Trata-se de um reducionismo que sujeita a vida a interesses financeiros, acarretando a dissolução de valores prévios e inviabilizando uma experiência plena, a vivência do pathos, deixando o ser humano ocupado exclusivamente com questões de natureza lógica. 
Para sustentar sua argumentação, Dewey (2003a, p. 106) cita trecho do livro "The psychology of reasoning", de Eugenio Rignano, pesquisador que investiga as bases biológicas do ser humano e defende que a análise do raciocínio é inteiramente delimitada pelo "jogo recíproco de duas atividades fundamentais e primordiais de nossa psique: a intelectual e a afetiva". A primeira consiste na evocação mnemônica de imagens do passado, e ambas constituem aspirações de nossa mente a determinado fim, para o qual nosso raciocínio se dirige. Assim, para satisfazer suas necessidades básicas, o organismo não utiliza apenas a capacidade intelectual, mas também a afetiva, modificando seu entorno em busca da meta desejada.

Quando o organismo é perturbado em seu equilíbrio com o ambiente, a ânsia e a necessidade de voltar ao estado normal o induzem a atos que provocam nova integração com o meio. Nesse estágio, "o raciocínio é uma fase da função genérica que provoca nova relação entre o organismo e as condições de vida, a qual, como outras fases, é controlada pela necessidade, pelo desejo e pelas satisfações progressivas" (DEWEY, 2003a, p. 106-107). Embora o organismo deseje alcançar tais satisfações, as experiências passadas são mantidas e evocadas quando nossa capacidade afetiva busca satisfazer suas exigências. Ocorre, então, a busca por mudanças ocasionadas em nossas formas de agir e sofrer experiências anteriores. $\mathrm{O}$ material do pensamento vem do passado, mas a sua direção é o futuro, rumo ao "desenvolvimento de um novo ambiente como condição de sustentação de um eu novo e totalmente integrado" (DEWEY, 2003a, p. 107).

Em "Arte como experiência" observa-se essa mesma abordagem da interação entre a fisiologia e a afetividade na consumação da experiência estética genuína, colocando em primeiro plano o tema das relações entre o organismo e o ambiente. Dewey $(2010$, p. 77) afirma que "só ao compartilhar relações ordeiras de seu meio é que o organismo garante a estabilidade essencial à vida". Surgindo após o momento de perturbação e conflito, essa estabilidade traz em si "os germes de uma consumação semelhante ao estético", sendo um fruto da necessidade de obter satisfações progressivas, o que só é possível quando o processo afetivo se funde ao intelectual.

Dewey (2010, p. 77) teoriza que a união do organismo com o meio tornase possível pelo uso adequado das emoções, material que permite a criação de propósitos. No afã de converter a "a simples emoção em um interesse pelos objetos, como condições de realização da harmonia", o "material da reflexão é incorporado pelos objetos como o significado deles". Interessado em alcançar essa união, o artista "não evita os momentos de resistência e tensão", mas os cultiva, não por si mesmos, "mas por suas potencialidades, introduzindo na consciência viva uma experiência unificada e total". 
Outra reflexão presente tanto no ensaio de 1926 quanto no livro de 1934 diz respeito à proximidade do estético com assuntos de natureza intelectual. Em "Arte como experiência", temos a defesa de que "a matéria suprema" tanto do artista quanto do intelectual é a experiência (DEWEY, 2010, p. 78). Em "Affective thought", Dewey (2003a) explica que tanto o sistema científico quanto o artístico incorporam princípios concernentes à relação da vida com o ambiente, em busca de satisfazer as mesmas necessidades fundamentais. $\mathrm{O}$ artista busca aplacar seus anseios no trabalho material, na forma, procurando dar significado a cada pincelada, de modo a criar um trabalho que apresente valor estético a quem o observa. O cientista realiza algo semelhante, porém utilizando símbolos concretos, fórmulas e signos que conduzam ao resultado desejado, procurando igualmente o equilíbrio com o meio por intermédio de ações progressivas.

Esse tema é recorrente em "Arte como experiência", sempre abordado com o propósito de destacar a relação entre os componentes estético e intelectual em trabalhos artísticos e científicos. Dewey (2010, p. 124-125) contraria certa opinião comum ao defender que a produção de uma obra de arte envolve tanto empenho intelectual como a produção científica, dizendo: "Toda ideia que desconhece o papel necessário da inteligência na produção de obras de arte se baseia na identificação do pensamento com o uso de um tipo de material específico de signos verbais e palavras". Pensar por meio das relações recíprocas entre as qualidades "é uma exigência tão severa ao pensamento quanto pensar em termos de símbolos verbais e matemáticos" (DEWEY, 2010, p. 125).

A terceira reflexão que se encontra tanto no ensaio de 1926 quanto em "Arte como experiência" diz respeito à presença da arte na educação. Em "Affective thought", o tema aparece associado à discussão acerca da proximidade entre ciência e arte, ocasião em que Dewey (2003a) explica que é função da arte promover a integração dos diversos níveis de nossa experiência cotidiana, tarefa particularmente relevante quando a tendência dominante consiste em tornar a vida departamentalizada em setores cada vez mais específicos e incomunicáveis. Nesses momentos, cabe às artes atuar sobre os valores que conduzem a educação, de modo a contrariar essa tendência tão desastrosa para a humanidade.

As páginas finais de "Arte como experiência" fazem eco a essas reflexões, analisando que certas teorias contemporâneas atribuem valores equivocados às artes, as concebendo segundo uma visão moral individualista e ocasionando a eliminação de seu papel formativo. Dewey (2010) considera que a arte instrui primordialmente por meio da comunicação, mas reconhece ser difícil elevá-la acima do que estamos habituados a pensar, como também é difícil sustentar o seu valor na educação. Para alcançar esse objetivo, a pedagogia, que age por "métodos muito literais que excluem a imaginação e não tocam nos desejos e emoções do homem", precisaria ser revista em prol de uma abordagem educacional genuinamente humanizadora. 


\section{Estética, cultura e educação}

Em 1926, Dewey publicou "Art in education-education in art", no qual valoriza a arte e da apreciação estética na vida e, em particular, na educação, como recurso destinado a romper com o modelo tecnicista cujo resultado é "desastroso por fortalecer a tendência ao profissionalismo, ou a configuração das mentes em formato de sulcos" (DEWEY, 2003b, p. 113). Dewey (2003b) comenta que o livro "Science and the modern world", do filósofo Alfred Whitehead, discute esse tema com o intuito de assegurar os elementos essenciais da formação humana, tornada cada vez mais técnica e menos humanizada.

Dewey (2003b) analisa a passagem em que Whitehead sugere que, ao entender tudo a respeito do sol, da atmosfera e da rotação da terra, podemos perder a capacidade de apreciar o pôr do sol, observação que põe ênfase no valor da apreciação estética e das artes, os únicos meios capazes de viabilizar a apreensão dos componentes individualizados da natureza e do homem. A vida moderna exige rapidez de raciocínio, agilidade para lidar com dispositivos diversos e habilidade técnica, excluindo do ambiente corporativo qualquer motivação associada à afetividade.

Esse hábito foi gradativamente transferido para outras esferas da vida, alcançando nossa experiência pessoal, relacionamentos e costumes, e nos tornando seres essencialmente técnicos. A realidade fundamentada na ciência e na indústria estabeleceu uma forma de educação baseada no intelecto e na informação associada à formação especializada em ramos de atuação. $\mathrm{O}$ resultado tem se mostrado danoso, pois fortalece a tendência ao profissionalismo, ao imediatismo, e conduz o ser humano a tomar abstrações como se fossem realidades (DEWEY, 2003b).

Dewey (2003b, p. 113) analisa que a implementação desse modo de vida leva ao controle e à posse de um ambiente fixo, contrariamente ao princípio de modificação do mundo contido na arte. Na tendência ora dominante, toda mudança é aversiva, nosso propósito se reduz ao conforto e à comodidade, mas "a civilização construída sobre esses princípios não pode satisfazer a alegria da alma, nem a frescura da experiência". Só os valores vívidos e transitórios das coisas expressos pelas artes podem alterar esse quadro desastroso.

Essa cultura cientificizada, que menospreza a apreciação estética, resulta "da disposição dos artistas (...) para colocar a arte em um pedestal, para fazer dela algo esotérico, algo além dos valores inerentes a todas as experiências das coisas em sua integridade, algo além das necessidades constantes do homem cotidiano" (DEWEY, 2003b, p. 114). No modelo cultural vigente, a arte é tratada como algo inalcançável, digno somente dos críticos e especialistas no assunto; relegada aos 
museus, a arte está longe do propósito de apreciação estética, sendo apresentada unicamente como algo a mais no status da classe dominante. Não se aprecia arte, mas se consome arte. Consumida pelo espírito prático e tecnicista, a arte se transforma em mera mercadoria.

Em "Arte como experiência", esse tema é retomado de modo semelhante. Dewey (2010, p. 124) argumenta em favor da experiência estética genuína na formação humana, destacando o vazio causado pelo acúmulo de falsas experiências. Habituados a um mundo em que as emoções são reprimidas e o tempo é visto como precioso, nossas experiências não amadurecem, apenas se avolumam, mas o acúmulo de impressões não passa de "um adejo e um gole bebido depressa". Embora nossa consciência seja atravessada por inúmeras sensações, "nada cria raízes na mente quando não há equilíbrio entre o agir e o receber"; nada se fixa no pensamento; nada se aloja reflexivamente, tudo se transfere mecanicamente para a realidade. Experiência acumulada não é, de fato, experiência, pois não tem caráter progressivo, não caminha para a consumação, constituindo apenas uma experiência inestética.

Em "Art in education - education in art", temos que indivíduos mecanicamente formados vivenciam emoções como estímulos mecânicos, sem perceber a "ideia da realidade que há nelas e por trás delas"; tornam-se bloqueadas as sensações mais humanas, o pathos, em prol de um novo e atraente ambiente técnico; os sentidos são perpetuados exclusivamente como excitações superficiais (DEWEY, 2003b, p. 113). "Arte como experiência" discute esse mesmo fenômeno como resultante da departamentalização do conhecimento e da própria vida, no que se incluem emoções e sentimentos. Dewey (2010) explica que a arte é relegada a espaços privados e peculiares, afastada da vida cotidiana e guardada em museus, resultando no divórcio entre o que concerne à prática e o que diz respeito à imaginação, entre o propósito significativo e o trabalho, entre o que remete à emoção e o que é relativo ao pensamento e à ação.

\section{Arte e trabalho docente}

O ensaio "Individuality and experience", de 1926, é dedicado a examinar a relação entre o desenvolvimento da individualidade e as responsabilidades do trabalho docente. Dewey (2003c, p. 56) contextualiza a história das instituições escolares utilizando a metáfora do pêndulo para explicar os extremos em que se situam as artes na educação: ora valorizando a "livre expressão", ora retornando a métodos impositivos. Estudos do filósofo Thomas Munro sobre os métodos 
de criação de imagens mostraram que alunos conduzidos pela espontaneidade e pelo "desenvolvimento interno" se sentem mais felizes. Notou-se mais tarde, que essa abordagem os torna apáticos e desinteressados devido à "ausência de desenvolvimento cumulativo e progressivo", o que deslocou o pêndulo para a posição contrária, colocando em cena a exigência de os alunos serem dirigidos por alguém mais maduro e experiente, uma autoridade que os conduza ao objetivo almejado.

Para Dewey (2003c), a metáfora do pêndulo sugere que a solução reside em identificar o ponto médio entre os extremos. Não se pode negar que o conhecimento advém da experiência espontânea, mas não se pode conceber a espontaneidade como o único fator responsável pelo progresso no aprendizado. No trabalho do carpinteiro, por exemplo, a aprendizagem é controlada por dois princípios fundamentais: a participação em algo inerentemente valioso, ou realizado por conta própria, e a associação dos meios com as consequências. Ao experimentar o significado dos diversos processos disponíveis para a realização do ofício, o aprendiz desenvolve o interesse pela habilidade e pela técnica, o que se transfere para os meios de sua efetivação. Portanto, os costumes, os métodos e os padrões de trabalho conjugam-se em uma tradição que se beneficia do adequado direcionamento dos desejos de cada aluno.

Para que um indivíduo se dedique a uma causa, é necessário haver desejo ou necessidade, sendo preciso também que compreenda a seu modo as relações entre meios e métodos, de um lado, e resultados, de outro. Ninguém pode ver pelo aprendiz; se ele não possui interesse próprio em se tornar um carpinteiro, ou se seu interesse é apenas superficial, visando tão somente obter um trabalho que o sustente, a tradição nunca irá integrar de fato os seus poderes como aprendiz, permanecendo como "um mero conjunto de regras mecânicas e mais ou menos sem sentido, que ele é obrigado a seguir para manter seu emprego e pagar seu salário" (DEWEY, 2003c, p. 58).

"Arte como experiência" aprofunda essa tese, teorizando que a experiência é um processo contínuo e duradouro que, somadas todas as suas partes, resulta em um todo completo que não pode ser reduzido a um simples passo e tampouco ao seu produto final.

Em uma experiência, o fluxo vai de algo para algo. À medida que uma parte leva a outra e que dá continuidade ao que veio antes, cada parte ganha distinção em si mesma. $\mathrm{O}$ todo duradouro se diversifica em fases sucessivas, que são ênfases de suas cores variadas (DEWEY, 2010, p. 111). 
A experiência torna-se significativa da mesma maneira como uma obra de arte se constrói por meio de pinceladas, episódios e ocorrências que se desmancham e se fundem na unidade. Como síntese de processos diversos, uma experiência é um intercâmbio contínuo mantido por várias outras experiências, mas que preserva seu caráter pessoal e se manifesta com mais clareza na conclusão. Essa conclusão, porém, não representa a consolidação de uma experiência autônoma, mas de um processo significativo de reflexão e atribuição significativa. Qualquer experiência cujo fim seja uma conclusão resulta de um movimento de premissas, ideias prévias que se congregam em uma ideia final (DEWEY, 2010).

"Arte como experiência" rompe com as teorias estéticas que atribuem à expressão e ao objeto expressivo características distintas, os isolando como coisas em si, desarticuladas do processo de criação. Essa desarticulação anula a individualidade própria do ato de produzir o objeto, sustentando que a expressão é mera descarga emocional. Dewey (2010) rejeita a oposição entre individual e universal, subjetivo e objetivo, liberdade e ordem, considerando que o único propósito dessas dicotomias é produzir artes inestéticas que pouco se relacionam com a experiência e nada contribuem para o progresso do caráter humano.

"Individuality and experience" transporta essa discussão para o campo educacional, mostrando que, ao ser orientado por um mestre que acredite em modelos fixos a serem reproduzidos, um aprendiz de carpinteiro será limitado em seus poderes pessoais, habilidades técnicas, capacidade de observação, imaginação, julgamento, e até mesmo em suas emoções. A tradição do ofício deixa de ser tradição para se tornar uma solução imutável, uma convenção absoluta. O mesmo ocorre com professores, governantes e juízes que vestem o manto do tradicional e se pronunciam não como eu, mas como um Senhor. O professor que se exprime como porta-voz de uma escola, de uma tradição clássica, suprime a integridade emocional e intelectual dos alunos, cuja "liberdade é reprimida, ficando atrofiado o crescimento de suas personalidades" (DEWEY, 2003c, p. 58-59).

O problema, portanto, não reside na oposição entre a sabedoria e a habilidade do passado, de um lado, e as capacidades individuais dos alunos, de outro, mas nos hábitos, padrões e ideias assumidos pelo professor. Dewey (2003c) propõe, então, a associação dinâmica entre teoria e prática: enquanto a primeira amplia, libera e dá significado à segunda, esta utiliza os suprimentos e materiais como teste e verificação da primeira, mantendo um ciclo sincero e vital. Quem se estabelece exclusivamente como prático ou como teórico comete um equívoco, pois não articula esses dois componentes.

Dewey (2003c, p. 59) conclui tecendo uma crítica ao pensamento educacional que propõe oferecer os alunos materiais e ferramentas e deixar que respondam segundo os seus próprios desejos; não se propõe nenhum plano, 
nem se sugere o que deva ser feito, acreditando que esta conduta representaria uma "transgressão injustificada contra a individualidade intelectual sagrada" dos aprendizes. Dewey (2003c, p. 60) se contrapõe a essa teoria que concebe o produto final como resultante unicamente da habilidade do pensamento, da "liberdade pessoal", e questiona: "quando a criança propõe ou sugere o que fazer, alguma consequência a ser alcançada, de onde vem a sugestão? Não há germinação espontânea na vida mental". Se a sugestão não vier do professor, virá de outra pessoa, da família ou dos colegas de rua.

Faz-se necessária, portanto, a presença do mestre, não o mestre autoritário, mas aquele que conheça os alunos, suas dificuldades, necessidades, experiências, graus de habilidade e conhecimentos, para assim compartilhar o que deve ou não ser feito e colocar o seu saber amadurecido à disposição dos aprendizes. Desse modo, poderá assegurar o resultado e garantir a ampliação das capacidades individuais, em substituição a sugestões provindas de fontes aleatórias. Deixar os alunos expostos ao método da "liberdade pessoal" serve apenas para confundir a natureza de seu pensamento, pois qualquer produto dele derivado será vago, "mero esboço de esboço", não uma ideia definitiva (DEWEY, 2003c, p. 59-60).

Dewey (2003c, p. 61-62) afirma que a verdadeira modelagem intelectual do fim ocorre durante e por causa das operações subsequentemente realizadas; o resultado advém de um processo que permite rever as práticas, exigindo uma reflexão a cada etapa, criando uma visão clara e organizada de uma finalidade. O pensamento torna-se explícito e objetivo no interior de um amplo movimento serial de execução, pois "uma pessoa toma consciência do que quer fazer e do que é apenas quando o trabalho está realmente completo". A originalidade e a independência do pensamento relacionam-se mutuamente com a execução intermediária, não constituindo a fonte de sugestão inicial. O professor deve apresentar aos alunos métodos e padrões durante a operação, observando suas práticas e os libertando de hábitos estreitos e fixos, muitas vezes autoritários e limitantes. Quanto maior e mais rica for a experiência do professor, mais chances ele terá para agir de "maneira libertadora".

Este assunto é retomado em "Arte como experiência", quando Dewey (2010, p. 143-144) discorre sobre a "impulsão", uma força situada na origem de toda experiência humana. Diferentemente do "impulso", essa força surge do interior do organismo, caminha para fora e adiante, constituindo o movimento do organismo como um todo e formando o estágio inicial de toda experiência. As crianças exibem múltiplas atitudes especializadas que não se constituem como experiências. A experiência só se torna possível quando uma atitude envolve a pessoa por completo, a levando a agir. Ignorar as atividades generalizadas em detrimento das especializadas é "a origem e a causa de todos os erros posteriores na interpretação da experiência”. 
A impulsão, portanto, não é a experiência em si, mas o seu ponto de partida. A experiência genuína é a síntese de processos que buscam a superação de uma necessidade individual que converte as emoções em interesse. A impulsão nascida da necessidade não sabe para onde ir, mas o movimento de resistência exercida contra ela, surgido do próprio pensamento, leva o indivíduo à reflexão. No decorrer de outras experiências, a experiência inicial ganha discernimento e significado. Assim, tanto o presente quanto o passado assumem relevância na constituição do devir, da experiência que conduz e impulsiona a humanidade (DEWEY, 2010).

\section{Considerações finais}

Os quatro ensaios de Dewey examinados neste trabalho possuem semelhanças temáticas pontuais como "Arte como experiência", constituindo, em conjunto, o que consideramos ser a gênese das teses contidas nesse livro. A discussão das relações entre o estético e o artístico feita em "Experience, nature and art" e a análise da conjugação entre processos fisiológicos, emocionais e imaginativos desenvolvida em "Affective thought" são retomadas na obra de 1934. Tais concepções filosóficas, por sua vez, compõem a base das reflexões sobre educação contidas em "Art in education - education in art", no qual se valoriza a arte como recurso útil ao desenvolvimento dos educandos, em oposição a modelos educacionais tecnicistas. O mesmo se aplica a "Individuality and experience", que trata da capacitação do docente para utilizar sua experiência pessoal como fator de crescimento de seus alunos.

Se a análise aqui realizada for plausível, podemos dizer que Dewey elaborou suas concepções sobre arte utilizando o mesmo método de produção que se pode identificar no tocante às suas ideias educacionais, ou seja, caminhando de textos menores a obras mais complexas. Mais ainda, é possível afirmar que suas discussões no campo da estética têm estreita relação com a educação. Embora somente dois dos ensaios examinados discutam temáticas educacionais, a leitura associada dos quatro textos evidencia o vínculo entre a teoria estética e as proposições de Dewey para a educação, o que confirma a tese de que "Arte como experiência" possui notável potencialidade para inspirar práticas educativas inovadoras, em especial no espaço escolar.

Sendo assim, podemos pleitear que "Arte como experiência" complementa e, ao mesmo tempo, produz avanços nas concepções veiculadas em "Democracia e educação", indicando que a teoria estética e as reflexões de Dewey sobre 
o valor da arte são partes relevantes de suas proposições educacionais. O entendimento conjugado desses dois setores de investigação enseja a proposta de uma pedagogia que coloque a experiência estética em posição privilegiada e permita conceber a relação entre professor e aluno à luz do componente mágico da poesia. Trata-se de uma educação poética que almeja romper os tradicionais dualismos entre teoria e prática, ciência e arte, intelecto e emoções, conhecimento formal e saberes cotidianos, métodos de livre expressão e teorias didáticas fundamentadas na autoridade.

Contrariando a tendência à departamentalização da vida, a pedagogia deweyana vai de encontro à cultura tecnicista que caminha a passos largos na educação atual. Dewey sugere um professor com qualidades artísticas, formado para - e interessado em - tornar a experiência um poderoso ingrediente na promoção do desenvolvimento de seus educandos. Essas proposições constituem a forma mais bem elaborada da tradição educacional que Crick (2010) denomina "pedagogia retórica". Iniciada com a primeira geração de sofistas da Grécia Clássica, essa tradição se apresenta, de modo mais ou menos explícito, em pensadores de diversas épocas ${ }^{4}$. As múltiplas dimensões - ética, política, comunicacional, afetiva etc. - da pedagogia retórica podem ser investigadas em muitos autores, tanto antigos quanto atuais, compondo um manancial de propostas que contribuem para fortalecer e redirecionar o trabalho dos educadores que se sentem tolhidos pelas tendências pedagógicas hoje dominantes.

\section{REFERÊNCIAS}

ANDRADE, Erika Natacha Fernandes; CUNHA, Marcus Vinicius. A contribuição de John Dewey ao ensino da arte no Brasil. Espacio, Tiempo y Educación, Salamanca, v. 3, n. 2, p. 301-319, jul./dez. 2016.

ANDRADE, Erika Natacha Fernandes; CUNHA, Marcus Vinicius. Sophistry in Vygotsky: contributions to the rhetorical and poetic pedagogy. Studies in Philosophy and Education, [S. l.], n. 39, p. 85-99, 2019.

BARBOSA, Ana Mae. Recorte e colagem: influências de John Dewey no ensino da arte no Brasil. São Paulo: Autores Associados: Cortez, 1982.

4 Ver, por exemplo, os trabalhos de Jalles e Cunha (2018), Sbrana e Cunha (2019), Andrade e Cunha (2019) e Carniel e Cunha (2020). 
BARBOSA, Ana Mae. Tópicos utópicos. Belo Horizonte: C/Arte, 1998.

BARBosA, Ana Mae. John Dewey e o ensino da arte no Brasil. 5. ed. São Paulo: Cortez, 2002.

BARBOSA, Ana Mae. A abordagem triangular no ensino das artes e culturas visuais. São Paulo: Cortez, 2010.

BARBOSA, Ana Mae. Arte-educação no Brasil. 7. ed. São Paulo: Perspectiva, 2012.

CARNIEL, Flávia Rocha; CUNHA, Marcus Vinicius. A sofística no discurso filosófico e educacional de Michel de Montaigne. Revista Eletrônica de Educação, São Carlos, v. 14, p. 1-17, jan./dez. 2020.

CRICK, Nathan. Democracy and rhetoric: John Dewey on the arts of becoming. Columbia: University of South Carolina, 2010.

CUNHA, Marcus Vinicius. John Dewey: educador e filósofo da democracia. História da pedagogia - John Dewey, São Paulo, n. 6, p. 6-17, dez. 2010.

DEWEY, John. Como pensamos. 2. ed. Tradução Godofredo Rangel. São Paulo: Nacional, 1953.

DEWEY, John. Democracia e educação: introdução à filosofia da educação. Tradução Godofredo Rangel e Anísio Teixeira. 3. ed. São Paulo: Nacional, 1959.

DEWEY, John. Experiência e educação. Tradução Anísio Teixeira. São Paulo: Nacional, 1971.

DEWEY, John. Experience, nature and art. In: ARCHAMBAULT, Reginald D. John Dewey on education: selected writings. Chicago: University of Chicago, 1974. p. 157-165.

DEWEY, John. A criança e o programa escolar. In: DEWEY, John. Vida e educação. Tradução Anísio Teixeira. 10. ed. Rio de Janeiro: Melhoramentos, 1978. p. 42-61.

DEWEY, John. Affective thought. In: BOYDSTON, Jo Ann; HICKMAN, Larry (org.). The collected works of John Dewey, 1882-1953. Electronic Edition, 2003a. v. 2, p. 105-111. Disponível em: http://pm.nlx.com/xtf/search?browse-collections=true. Acesso em: 30 jan. 2021.

DEWEY, John. Art in education - and education in art. In: BOYDSTON, Jo Ann; HICKMAN, Larry (org.). The collected works of John Dewey, 1882-1953. The later works, 1925-1953. Electronic Edition, 2003b. v. 2, p. 112-116. Disponível em: http:// pm.nlx.com/xtf/search?browse-collections=true. Acesso em: 30 jan. 2021.

DEWEY, John. Individuality and experience. In: BOYDSTON, Jo Ann; HICKMAN, Larry (org.). The collected works of John Dewey, 1882-1953. The later works, 19251953. Electronic Edition, 2003c. v. 2, p. 56-62. Disponível em: http://pm.nlx.com/xtf/ search?browse-collections=true. Acesso em: 30 jan. 2021. 
DEWEY, John. Logic: the theory of inquiry. In: BOYDSTON, Jo Ann; HICKMAN, Larry (org.). The collected works of John Dewey, 1882-1953. The later works, 19251953. Electronic Edition, 2003d. v. 12, p. 4-528. Disponível em: http://pm.nlx.com/xtf/ search?browse-collections=true. Acesso em: 30 jan. 2021.

DEWEY, John. My pedagogic creed. In: BOYDSTON, Jo Ann; HICKMAN, Larry (org.). The collected works of John Dewey, 1882-1953. The Early Works of John Dewey, 18821898. Electronic Edition, 2003e. v. 5, p. 85-96. Disponível em: http://pm.nlx.com/xtf/ search?browse-collections=true. Acesso em: 30 jan. 2021.

DEWEY, John. The school and society. In: BOYDSTON, Jo Ann; HICKMAN, Larry (org.). The collected works of John Dewey, 1882-1953. The Middle Works, 18991924. Electronic Edition, 2003f. v. 1, p. 3-110. Disponível em: http://pm.nlx.com/xtf/ search?browse-collections=true. Acesso em: 30 jan. 2021.

DEWEY, John. Teoria da valoração. In: DEWEY, John. A valoração nas ciências humanas. Tradução Marcus Vinicius da Cunha, Ana Rachel L. Cianflone e Erika Natacha F. de Andrade. Campinas: Autores Associados, 2009.

DEWEY, John. Arte como experiência. Tradução Vera Ribeiro. São Paulo: Martins Fontes, 2010.

JALLES, Aglaia Ruffino; CUNHA, Marcus Vinicius. A sofística no discurso educacional de Agostinho de Hipona. Cadernos CIMEAC, Uberaba, v. 8, n. 2, p. 18-37, 2018.

REIS, Magali; BAGOLIN, Luiz Armando. Arte como experiência. Cadernos de Pesquisa, São Paulo, v. 41, n. 142, p. 314-319, 2011.

SBRANA, Roberta Aline; CUNHA, Marcus Vinicius. A pedagogia retórica em JeanJacques Rousseau e John Dewey. Teoria e Prática da Educação, Maringá, v. 22, n. 2, p. 41-55, maio/ago. 2019.

VALDEMARIN, Vera Teresa. História dos métodos e materiais de ensino: a escola nova e seus modos de uso. São Paulo: Cortez, 2010.

Texto recebido em 12/07/2021.

Texto aprovado em 24/08/2021. 